TRUCCONE, Santiago "Un concepto de daño y sus consecuencias para la parte general del derecho penal".

Polít. crim. Vol. 12, № 24 (Diciembre 2017), Art. 14, pp. 1184-1210.

[http://www.politicacriminal.cl/Vol_12/n_24/Vol12N24A14.pdf]

\title{
Un concepto de daño y sus consecuencias para la parte general del derecho penal
}

\section{A concept of harm and its consequences for Criminal law's general part}

\author{
Santiago Truccone Borgogno \\ Universidad Nacional de Córdoba \\ santiagotruccone@gmail.com
}

\section{Resumen}

En este trabajo intentaré defender una noción combinada de daño de acuerdo a la cual existen dos tipos de daños cualitativamente diferentes. Asimismo, defenderé un modo en que la gravedad de los diferentes daños puede ser graduada. Derivado de lo anterior, extraeré tres principios sobre la fuerza de las razones en contra de dañar. La tesis defendida proporcionará herramientas para resolver algunos problemas de la parte general de derecho penal. En relación al tipo penal, mostraré que la noción de daño defendida puede ayudar a resolver casos de cursos causales alternativos e hipotéticos. En referencia a la antijuridicidad, mostraré que la clasificación de la gravedad de los daños propuesta ayuda a distinguir qué casos de estado de necesidad deben considerarse como justificación y cuales como excusa. En referencia a la culpabilidad, mostraré que los principios sobre la diferente fuerza de las razones en contra de dañar ayudan a aportar criterios claros para la individualización de la pena a imponer por la comisión de un delito.

Palabras clave: Concepto de daño, gravedad de daño, cursos causales hipotéticos, estado de necesidad, graduación de la pena.

\begin{abstract}
In this work, I will support a combined notion of harm according to with there are qualitatively different harms. I will support a way in which the severity of harms could be measured. Then, I will provide three principles about the strength of the reasons against harming. The supported thesis will provide some tools to solve some problems of the general part of criminal law. In relation to the analytical stratum of statutory description of an offence, I will show that the defended notion of harm could help to solve cases of hypothetical and alternative causal courses. In relation to the analytical stratum of unlawfulness (or wrongfulness), I will show that the proposed ranking of the severity of harms help us to distinguish between cases of necessity as justification and necessity as excuse. In relation to the analytical stratum of culpability, I will show that the principles regarding the strength of the reasons against harming help us to supply straightforward criteria to measure the punishment to impose for having committed some crime.
\end{abstract}

Key words: Concept of harm, severity of harm, hypothetical causality, necessity, right punishment. 
TRUCCONE, Santiago "Un concepto de daño y sus consecuencias para la parte general del derecho penal".

\section{Introducción}

La mayor parte de la discusión en derecho penal sobre el daño ha estado signada por el debate referido a si el principio de daño es o no un buen principio para justificar moralmente la censura penal de conductas. Este principio, cuya formulación original se debe a John Stuart Mill afirma -en términos generales- que tenemos razones para criminalizar conductas si están relacionadas de un modo adecuado con un daño identificable $^{1}{ }^{2}$. Sin embargo, existe otra discusión a la que se le ha prestado menos atención. Me refiero a aquella que versa sobre el concepto de daño que tal principio debe adoptar. Una noción adecuada de daño, como parte del principio de daño, permite no sólo aportar claridad al debate referido a la justificación moral de prohibiciones penales, sino que también proporciona servicios adicionales al momento de resolver algunos problemas propios de la Parte General del Derecho Penal. En este trabajo intento aportar claridad en este segundo punto. Intentaré defender un concepto de daño capaz de ayudar a resolver algunos problemas propios de la Parte General del Derecho Penal. Así, por un lado, defenderé una noción de daño que dé cuenta de tres requisitos que cualquier noción de daño exitosa debería satisfacer. Dicha noción deberá explicar: 1) qué es sufrir un daño; 2) por qué es malo sufrir un daño; y 3) dar alguna idea sobre cómo medir la gravedad de los diferentes tipos de daño ${ }^{3}$. Por otro lado, analizaré qué consecuencias se siguen de la noción de daño previamente diagramada para la Parte General del Derecho Penal.

Concretamente, primero, en cuanto al concepto de daño, apelaré a una noción combinada de daño de acuerdo a la cual un sujeto sufre un daño tanto cuando el estado en el que se encuentra está debajo de un umbral normativamente definido como cuando se encuentra en

\footnotetext{
${ }^{1} \mathrm{La}$ formulación original de J. S. Mill fue la siguiente "El único fin por el cual el poder puede ser correctamente ejercitado sobre cualquier miembro de una comunidad civilizada, en contra de su voluntad, es evitar el daño a otros" (MILL, John Stuart, On Liberty, [D. Bromwich and G. Kateb (Eds.)], New Haven: Yale University Press, 2008 [1859], pp.80). Sin embargo, la formulación de tal principio fue variando con el correr de los años. Por ejemplo, a diferencia de Mill quien creía que el daño a otros era la única razón para criminalizar conductas, Joel Feinberg creía que es sólo una buena razón (FEINBERG, Joel, Harm to Others: The Moral Limits of Criminal Law, Vol I., Oxford: Oxford University Press, 1984, p. 26). Asimismo, ambas posiciones pueden ser consideradas como versiones directas del principio del daño debido a que justifican una prohibición sólo si la acción censurada es susceptible, por sí misma, de ser dañosa para otras personas. Otros autores, como Gardner y Shute, apoyan una versión indirecta. Para ellos es suficiente para cumplir con las demandas del principio de daño que, si la acción no hubiese sido criminalizada, eso hubiera sido dañoso (GARDNER S. y SHUTE S., "The Wrongness of Rape" en: HORDER, Jeremy (Ed.), Oxford Essays in Jurisprudence: Fourth Series, Oxford: Oxford University Press, 200, pp. 199-217).

${ }^{2}$ La mayoría de los debates sobre el principio de daño han girado en referencia cuestión relativa a si el principio de daño es una herramienta idónea para identificar el tipo específico de incorrección moral capaz para ser adoptada por los estados liberales como criterio válido de justificación de censura penal. Este debate tuvo su origen en las discusiones suscitadas, primero, entre el mismo J.S. Mill y J.F Stephen, y, luego, entre H.L.A Hart y Lord Devlin. En la actualidad se ha visto un resurgir del moralismo legal de la mano de las posiciones de John Gardner y Antony Duff. Sobre esto véase HART, H.L.A., Law, Liberty and Morality, Oxford: Oxford University Press, 1962; DEVLIN, Patrick, "Morals and the Criminal Law", en: WASSERSTROM, R. (Ed.), Morality and the Law, Belmont: Wadsworth Publishing Company, 1971[1965], pp. 24-48; DUFF, R. A., Answering for Crime: Responsibility and Liability in the Criminal Law. Oxford: Hart Publishing, 2007, Cap. 6; NINO, Carlos S., Los Límites a la Responsabilidad Penal: una Teoría Liberal del Delito, Buenos Aires: Astrea, 1980, pp. 269-304.

${ }^{3}$ En esto sigo a HANSER, Matthew, "The Metaphysics of Harm", Philosophy and Phenomenological Research, Vol. LXXXVII, Nº 2 (2008), pp. 421-450.
} 
Polít. crim. Vol. 12, № 24 (Diciembre 2017), Art. 14, pp. 1184-1210.

[http://www.politicacriminal.cl/Vol_12/n_24/Vol12N24A14.pdf]

un estado tal que, si dicho estado no hubiese tenido lugar, el sujeto habría estado en uno mejor. Llamaré a la primera clase de daño absolutos y a la segunda relativos. Segundo, afirmaré que sufrir daños absolutos es malo porque afecta el derecho de una persona a tener un nivel mínimo de bienestar; en tanto que sufrir daños relativos es malo porque de ese modo las personas tienen un nivel de bienestar que es peor que aquel que habrían tenido de otro modo. Así, en tercer lugar, en cuanto a la gravedad de los daños, intentaré mostrar que: (a) si los daños son cualitativamente idénticos, sufrir una mayor cantidad de unidades de daño es peor que sufrir una cantidad menor; (b) si los daños son cualitativamente diferentes, es más grave sufrir un número $\mathrm{X}$ de unidades de daño absoluto que el mismo número de unidades de daño relativo; (c) sufrir $\mathrm{X}$ unidades de daño absoluto $\mathrm{y}$ adicionalmente $\mathrm{Y}$ unidades de daño relativo es peor que sufrir solo $\mathrm{X}$ unidades de daño absoluto. Derivado de cada una de estas afirmaciones [(a)(b)(c)] elaboraré ciertos principios sobre la fuerza de las razones en contra de dañar. En cuarto lugar, mostraré cómo las conclusiones alcanzadas en las tres primeras secciones de este trabajo ayudan a resolver varias cuestiones espinosas del derecho penal. En referencia al tipo penal, mostraré cómo la tesis combinada de dañar puede ayudar a resolver lo que los teóricos penales han llamado problema de los cursos causales hipotéticos y de causalidad múltiple. En segundo lugar, mostraré que la distinción cuantitativa y cualitativa sobre la gravedad de los distintos daños sufridos puede ser de utilidad para distinguir situaciones de falta de antijuridicidad o meramente falta de culpabilidad (lo que se conoce como el problema de la distinción entre justificación y excusa). En tercer lugar, mostraré que los principios sobre la fuerza de las razones en contra de dañar sirven para graduar la culpabilidad (responsabilidad) de los agentes cuando han realizado un injusto penal.

\section{Estados de daño}

\subsection{Concepto}

¿Qué es exactamente sufrir un daño? Existen varias respuestas a esta pregunta, sin embargo, podemos comenzar afirmando que sufrir un daño significa estar en un estado que se encuentra por debajo de alguna línea de base. Ahora bien ¿cuál es la línea de base relevante para afirmar que alguien está sufriendo un daño? Veamos el siguiente ejemplo:

\subsubsection{CASO I-(Juan):}

Juana está embarazada y tiene planeado realizar un viaje de placer a Centroamérica. Debido a la posibilidad de que se contagie con el virus Zika, el médico le ha aconsejado que no realice el viaje. El problema es que, de contagiarse, se producirá que el hijo que porta en su seno -Juan- nazca con microcefalia. Esta condición impide un desarrollo cerebral completo ocasionando cierto retraso en las capacidades intelectuales. Juana hace caso omiso al consejo del médico y viaja a Centroamérica. Ella desea tener un hijo con microcefalia dado que, de ese modo podrá vivir el resto de su vida con una persona que necesita de sus cuidados. Efectivamente Juana se contagia con el virus Zika. Como resultado nace Juan con microcefalia y cierto retraso en sus capacidades intelectuales. 
TRUCCONE, Santiago "Un concepto de daño y sus consecuencias para la parte general del derecho penal”.

¿Está Juan sufriendo un daño? La respuesta parece obviamente afirmativa. El modo mayormente aceptado de explicar por qué alguien está sufriendo un daño es apelar a la noción contrafáctica de daño. De acuerdo a una formulación plausible de tal noción, un sujeto está sufriendo un daño cuando está en un estado que es peor que otro en el que habría estado si no se hubiese actuado con respecto a él del modo en que se lo hizo ${ }^{4}$. Aquí, si Juana no hubiese viajado a Centroamérica y no se hubiese contagiado de Zika, Juan no hubiese nacido con microcefalia y cierto retraso en sus capacidades intelectuales. Por tanto, dado que Juan se encuentra en un estado que es peor que aquel en el que habría estado si Juana no hubiese actuado como lo hizo, la noción contrafáctica nos permite afirmar que Juan está sufriendo un daño. De acuerdo a esta noción, la línea de base relevante para afirmar que se está sufriendo un daño está dada por el estado en el que el sujeto habría estado si el agente no hubiese obrado como lo hizo. En estos casos, afirmamos que el daño sufrido es malo dado que la cantidad de bienestar del sujeto afectado es más baja que aquella que habría tenido si el agente no hubiese obrado como lo hizo. Así, Juan está sufriendo un daño porque se encuentra en un estado peor que aquel en el que habría estado si su madre hubiera obrado de otro modo. Aunque esta noción de daño parece plausible, encuentra problemas casos del tipo del siguiente:

\subsubsection{CASO II - (María):}

Marta acaba de regresar de Centroamérica. Ella acude al médico porque pretende concebir un niño. El médico le informa que se ha contagiado del virus Zika y que, si concibe ahora, su hijo nacerá con microcefalia. El médico le aconseja que espere un mes antes de concebir. De ese modo se asegurará que el virus haya desaparecido y su hijo no nazca con esa condición. Sin embargo, Marta hace caso omiso al consejo del médico y concibe su hijo antes transcurrido el mes. Ella desea tener un hijo con microcefalia dado que, de ese modo, podrá vivir el resto de su vida con una persona que necesita de sus cuidados. Como resultado, nace María con microcefalia y cierto retraso en sus capacidades intelectuales.

¿Está María sufriendo un daño? Dado que María, al nacer con cierto retraso en sus capacidades intelectuales, está en el mismo estado que Juan parece que está sufriendo un daño. Sin embargo, no puede sostenerse que la acción que causó que María se encuentre en tal estado haya empeorado algún estado o condición en la que ella habría estado de otro modo. Si Marta hubiese esperado un mes para concebir, María no estaría en un mejor estado; en ese caso, nunca habría existido. Esto es así porque cada persona surge de un espermatozoide y de un óvulo particular. Si una persona no hubiese sido concebida en el espacio de un mes alrededor del momento en que fue concebida, de hecho, nunca habría existido ${ }^{5}$. Por tanto, si María no hubiese sido concebida en el espacio de un mes en relación al momento en que fue concebida, de hecho, nunca habría existido. Podría haber existido en su lugar otra persona que hubiese sido el hijo de Marta, pero este niño no habría sido María. ¿Significa esto que María no está sufriendo un daño? Luego de analizar nuevamente el caso, y por más que María no esté en un estado peor que aquel en el que habría estado si su madre hubiese obrado de modo diferente, parece que ella está sufriendo un daño. ¿Cómo

\footnotetext{
${ }^{4}$ Esta formulación corresponde a la proporcionada por Joel Feinberg (FEINBERG, Harm to Others, cit. nota $\left.\mathrm{n}^{\circ} 1, \mathrm{p} .31\right)$.

${ }^{5}$ PARFIT, Derek, Reasons and Persons, Oxford: Clarendon Press, 1987, pp. 351-355.
} 
Polít. crim. Vol. 12, № 24 (Diciembre 2017), Art. 14, pp. 1184-1210.

[http://www.politicacriminal.cl/Vol_12/n_24/Vol12N24A14.pdf]

explicar esta intuición? Un modo de hacerlo es apelar a la noción de umbral de daño ${ }^{6}$. De acuerdo a ésta, una persona está sufriendo un daño si se encuentra en un estado que está por debajo del estado en que ella debería haber estado ${ }^{7}$. Obviamente, esto requiere que sea posible especificar un nivel de bienestar respecto del cual el derecho de una persona es violado si no cumplimos con nuestro deber negativo de no causar que una persona esté debajo de dicho estándar ${ }^{8}$. Aquí, el umbral de daño es un estándar externo que funciona del mismo modo que el estado contrafáctico en el que se habría encontrado un sujeto bajo la noción contrafáctica9 ${ }^{9}$. De acuerdo a esta posición, la línea de base en relación a la cual debemos comparar el estado en el que se encuentra una persona para afirmar que está sufriendo un daño está dada por un umbral normativamente definido, es decir, por el estado en que la persona afectada debería o tiene derecho a estar. En este caso, sufrir un daño no es malo porque un sujeto tenga un nivel de bienestar peor que aquel que habría tenido de otro modo, sino porque se ha violado su derecho a tener un nivel mínimo de bienestar. Como María, al nacer con cierto retraso en sus capacidades intelectuales, se encuentra en un estado por debajo del umbral relevante de bienestar, teniendo - de este modo- un nivel de bienestar peor que aquel que las personas tienen derecho a tener, ella está sufriendo un daño.

La noción de umbral de daño permite explicar tanto por qué Juan (CASO I) como María (CASO II) están sufriendo un daño. Ambos sujetos, al nacer con microcefalia y retraso intelectual, están en el mismo estado por debajo del umbral de daño. El nivel de bienestar de ambos es peor que aquel que tienen derecho a tener. Así, parece que el umbral de daño es la noción que debemos utilizar para saber cuándo alguien sufre un daño. De acuerdo a ella, sobre la base del daño causado, podemos objetar conductas que tengan efectos adversos sobre el bienestar de las personas tanto en los casos donde la identidad de los afectados depende de nuestras acciones como en aquellos en los que no. Sin embargo, dicha tesis no se encuentra exenta de problemas. Analicemos el siguiente caso:

\subsubsection{CASO III - (Pedro):}

Petra se somete a un proceso de diagnóstico pre-natal mediante el cual trata de controlar el estado de salud de la criatura que porta en su seno. El médico le informa que los estudios han mostrado que su hijo es genéticamente perfecto y, por tanto, si el embarazo continúa en sus carriles normales, su hijo tendrá no sólo casi ningún riesgo de padecer cáncer, problemas cardíacos, o Alzhéimer, sino también una inteligencia superior.

\footnotetext{
${ }^{6}$ MEYER, Lukas, "Past and Future: The Case for a Threshold Notion of Harm", en: MEYER, L.; PAULSON, S.; POGUE, T. (Eds.), Rights, Culture, and the Law: Themes from the Legal and Political Philosophy of Joseph Raz, Oxford: Oxford University Press, 2003, pp. 143-159, p. 147; MEYER, Lukas, "Intergenerational Justice", en: ZALTA, Edward N. (Ed.), The Stanford Encyclopaedia of Philosophy, Stanford: Stanford University Metaphysics Research Lab, 2015, pp. 1-101, p. 21.

${ }^{7}$ MEYER, "Past and Future" cit. nota n ${ }^{\circ} 6$, p. 147.

${ }^{8}$ MEYER Lukas; ROSER, Dominic, "Enough for the Future", en: GOSSERIES, A.; MEYER, L. (Eds.), Intergenerational Justice, Oxford: Oxford University Press, 2009, pp. 219-248, p. 229.

${ }^{9}$ DILLARD, Carter, "Procreation, Harm and the Constitution", Northwestern University Law Review, Vol. 105 (2010), pp, 5-17, p. 8.
} 
TRUCCONE, Santiago "Un concepto de daño y sus consecuencias para la parte general del derecho penal”.

Petra tiene planeado realizar un viaje de placer al sur de la Argentina. El médico le aconseja que no realice tal viaje dado que el feto se encuentra en una etapa importante de su desarrollo. Si ella no realiza reposo por unas semanas, la consecuencia sería que el hijo que porta en su seno -Pedro- pierda cierto grado de inteligencia superior.

Petra piensa que no vale la pena sacrificar su viaje por el bienestar de su niño, de modo que hace caso omiso al consejo del médico y viaja al sur de la Argentina. Efectivamente el estrés del vuelo ocasiona que Pedro nazca con una inteligencia mayor a la que se considera normal, pero menor a la inteligencia superior que habría tenido.

¿Está Pedro sufriendo un daño? No podemos afirmar que Pedro está sufriendo un daño si apelamos a la noción de umbral de daño. Nacer con inteligencia mayor a la que se considera normal no puede estar debajo de ningún umbral de daño definido de modo plausible. Sin embargo, parece que él está sufriendo un daño. Si el estado en el que se encuentra no hubiese tenido lugar, él estaría en uno mejor. Para explicar por qué Pedro está sufriendo un daño, parece que debe ser abandonada la noción de umbral de daño y, en su lugar, debe apelarse -nuevamente- a la noción contrafáctica de daño. Después de todo, Pedro está en un estado que es peor que otro en el que habría estado si su madre hubiese obrado de modo diferente. Pero si debemos tomar en consideración la tesis contrafáctica nuevamente para explicar por qué Pedro (CASO III) sufre un daño, aunque podamos explicar -de este modo- el daño que sufre Juan (CASO I), no podremos explicar por qué María (CASO II) lo sufre. Como hemos visto, no es verdadero que María esté en un estado que sea peor que otro en el que habría estado si su madre no hubiese actuado como lo hizo. En ese caso, ella no habría existido.

Parece que ninguna de las dos nociones puede explicar por qué en los tres casos la persona afectada está sufriendo un daño. Esto hace que regresemos al punto inicial. Parece que no podemos objetar de modo consistente acciones como las de Marta, sin encontrarnos con problemas en los demás casos. ¿Hay alguna salida? Creo que sí. Lukas Meyer ha propuesto interpretar como condición necesaria de dañar a la disyunción entre las acciones que causan que alguien esté por debajo del umbral de daño y las acciones que causan que alguien se encuentre en un estado peor que otro en el que se habría estado. De acuerdo a su tesis disyuntiva:

"(Disyuntiva): una acción (o inacción) en el momento t1 daña a alguien solo si o [a] el
agente causa (permite) de ese modo que esta persona esté en un estado por debajo del
umbral, y, si el agente no puede evitar causar daño en este sentido, no minimiza el
daño; o [b] el agente causa que esta persona esté en una peor condición en algún
momento posterior t 2 de aquella en la que esa persona habría estado en t 2 si el agente
no hubiese interactuado con esta persona en absoluto."

Como se observa, esta "noción disyuntiva" condensa tanto afirmaciones sobre los estados de daño como sobre las acciones dañosas. Un estado de daño es aquel en el que se encuentra la persona que sufre un daño, en tanto que una acción dañosa es aquella que causa que una persona esté en un estado de daño. Estados de daño y acciones dañosas

\footnotetext{
${ }^{10}$ MEYER, "Intergenerational Justice”, cit. nota $n^{\circ}$ 6, p. 31.
} 
Polít. crim. Vol. 12, № 24 (Diciembre 2017), Art. 14, pp. 1184-1210.

[http://www.politicacriminal.cl/Vol_12/n_24/Vol12N24A14.pdf]

integran distintos enfoques sobre dañar. Existen dos enfoques opuestos al respecto. Por un lado, los enfoques relativos a los efectos afirman que una persona daña a otra en virtud de los efectos de la acción dañosa sobre el bienestar de un individuo. Por otro lado, las nociones relativas a la acción afirman que una persona daña a otra en virtud de la diferencia que una acción marca en el bienestar de una persona ${ }^{11}$. Con respecto a los estados de daño, estos dos enfoques se diferencian en lo siguiente. Mientras para los enfoques relativos a los efectos, un sujeto sufre un daño en virtud del tipo de estado en el que se encuentra, los enfoques relativos a la acción sostienen que para afirmar que un sujeto sufre un daño es necesario que en ausencia de la acción que causó tal estado de cosas el sujeto afectado no esté en un estado de daño. De este modo podemos distinguir, al menos, dos versiones diferentes de la tesis disyuntiva referida a los estados de daño:

\section{(Noción disyuntiva de los estados de daño relativa a la acción)}

Una persona sufre un daño solo si:

[a] se encuentra en un estado por debajo del umbral y no se hubiese encontrado en dicho estado si el agente no hubiese interactuado con ella en absoluto, o

[b] está en un estado peor que aquel en el que habría estado si no se hubiese interactuado con ella en absoluto.

(Noción disyuntiva de los estados de daño relativa a los efectos)

Una persona sufre un daño solo si:

[a] se encuentra en un estado por debajo del umbral, o

[b] está en un estado E tal que, si E no hubiese tenido lugar, ella se habría encontrado en un estado mejor.

Aunque la primera posibilidad parece más cercana a la noción disyuntiva de dañar de Lukas Meyer $^{12}$, creo que es preferible la segunda. Para ver por qué esto es así considérese el siguiente caso:

(El matón y el usurero) Supóngase que un criminal quiere robar la tienda de joyas de Joaquín. Dado que el robo será más fácil si Joaquín no está en ella, el criminal contrata a un matón para que le quiebre las piernas el día anterior al robo. Cuando el matón llega a la casa de Joaquín, sin embargo, encuentra que el usurero local ya ha roto sus piernas ${ }^{13}$.

En esta clase de casos, de acuerdo a la noción combinada de los estados de daño relativa a la acción (y a cualquier noción de los estados de daño relativa a la acción) no es posible afirmar que Joaquín está sufriendo un daño. El estado en el que se encuentra no satisface ni la condición [a] ni la [b] de dicha tesis. En ausencia de la acción del usurero local, Joaquín se habría encontrado en el mismo estado. Joaquín no está en un estado en el que no hubiese estado si el agente no hubiese interactuado con él en absoluto, tal y como requiere la

\footnotetext{
${ }^{11}$ GARDNER, Molly, "On the Strength of the Reason Against Harming", Journal of Moral Philosophy, Vol. 14, $\mathrm{N}^{\circ}$ 1(2017), pp. 1-15, pp. 3-6; GARDNER, Molly, "The Problem of Justified Harm", Ethical Theory and Moral Practice (inédito), 2017, pp. 1-19.

${ }^{12}$ Véase MEYER, "Intergenerational Justice" cit. nota, n 6, p. 93.

${ }^{13}$ He modificado ligeramente el ejemplo de HANSER, Mathew, "The Metaphysics of Harm", Philosophy and Phenomenological Research, Vol. LXXXVII, N 2 (2008), pp. 421-450.
} 
TRUCCONE, Santiago "Un concepto de daño y sus consecuencias para la parte general del derecho penal".

cláusula [a]; y tampoco se habría encontrado en un mejor estado si el agente no hubiese interactuado con él en absoluto, tal y como requiere la cláusula [b]. Por lo tanto, de acuerdo a la noción combinada de los estados de daño relativa a la acción, Joaquín no está sufriendo un daño. Si Joaquín no está sufriendo un daño, no puede considerarse que la acción del usurero lo ha dañado, por más que el primero tenga sus piernas rotas a consecuencia de la acción del segundo. Esto no parece plausible. Claramente Joaquín, al tener sus piernas rotas, está sufriendo un daño.

Sin embargo, si apelamos a la noción disyuntiva sobre los estados de daño relativa a los efectos no existen problemas en afirmar que Joaquín está sufriendo un daño. El estado en el que se encuentra satisface no sólo la cláusula [a] de dicha tesis dado que está debajo del umbral; sino que, también, satisface la cláusula [b]: si el estado en el que se encuentra Joaquín no hubiese tenido lugar, él habría estado en uno mejor. De esta manera podemos sostener que la acción del usurero local, que ha causado que Joaquín sufra un daño, es dañosa. Como esto es así, creo que debemos aceptar la versión relativa a los efectos de la noción disyuntiva de los estados de daño, la que de aquí en adelante será llamada noción combinada:

(Combinada): una persona sufre un daño solo si:

[a] está en un estado por debajo del umbral, o

[b] está en un estado E tal que, si E no hubiese tenido lugar, esa persona se habría encontrado en un estado mejor.

Si volvemos a los casos iniciales, esta noción combinada es capaz de explicar por qué Juan María y Pedro están sufriendo daños. En cada caso, la persona afectada satisface al menos una condición de dicha tesis. Pedro (CASO III) sufre un daño porque se encuentra en un estado tal que, si el estado en el que está no hubiese tenido lugar, habría estado en uno mejor. Por lo tanto, el estado en el que se encuentra satisface la condición [b] de la tesis combinada. Cuando alguien se encuentra en un estado dañado que satisface dicha condición, afirmaremos que está sufriendo un daño relativo, dado que el estatus de daño de dicho estado requiere una comparación entre dos estados posibles: el estado en el que está el sujeto afectado y el estado en el que habría estado si el estado en el que se encuentra no hubiese tenido lugar. Es decir, Pedro sufre un daño porque si el estado en el que se encuentra no hubiese tenido lugar, su nivel de bienestar sería mayor. María (CASO II) está en un estado que se encuentra debajo del umbral y, por lo tanto, satisface la condición [a] de la tesis combinada. Podemos llamar a esta clase de daño absoluto dado que el estatus de daño no requiere ninguna comparación entre dos estados posibles. El estatus de daño deriva del hecho de que el nivel de bienestar del sujeto afectado es peor que aquel que tiene derecho a tener. Juan (CASO I) debido a que está en un estado tal que se encuentra tanto debajo del umbral de daño, como que, si dicho estado no hubiese tenido lugar, él habría estado en uno mejor, satisface tanto la condición [a] como [b] de la noción combinada de daño. Él está sufriendo tanto un daño absoluto como uno relativo. Puesta en estos términos, la noción combinada de daño puede explicar por qué las tres personas afectadas están sufriendo un daño y, presumiblemente, por qué las acciones que han causado que las personas sufran esos daños merecen ser consideradas incorrectas. 
Polít. crim. Vol. 12, № 24 (Diciembre 2017), Art. 14, pp. 1184-1210.

[http://www.politicacriminal.cl/Vol_12/n_24/Vol12N24A14.pdf]

\subsection{Maldad de los daños}

Puede surgir una preocupación aquí. Hemos afirmado que sufrir un daño absoluto es malo porque el nivel de bienestar del sujeto afectado es peor que el nivel de bienestar mínimo que las personas tienen derecho a tener; en tanto que sufrir un daño relativo es malo porque el nivel de bienestar del sujeto afectado es menor que aquel que habría tenido si el estado en el que se encuentra no hubiese tenido lugar. Uno podría afirmar que no estamos en presencia de dos clases de males sino de uno sólo. Sin embargo, esta última afirmación es errónea.

Podemos observar por qué se está en presencia de dos males diferentes si tenemos en cuenta que no en todos los casos en los que un sujeto se encuentra en un estado debajo del umbral -sufriendo de ese modo un daño absoluto- estará sufriendo también un daño relativo. Sólo lo estará en los casos en los que pueda afirmarse que el sujeto habría estado en un mejor estado de otro modo. Así, cuándo nos preguntamos por qué es malo sufrir un daño absoluto, sólo tenemos que tener en cuenta que el sujeto afectado se encuentra por debajo de cierto nivel mínimo de bienestar que tiene derecho a tener. Este hecho es suficiente para afirmar que es malo que esté sufriendo un daño. El hecho de que haya podido o no encontrarse en un mejor estado es irrelevante para afirmar porqué sufrir este tipo de daño es malo. Podemos marcar dicho nivel en aquel donde las personas están ligeramente por encima del estado en el que tienen sus necesidades básicas satisfechas ${ }^{14}$. De esta manera sólo se estará sufriendo un daño absoluto cuando una persona se encuentre en un estado cuyo nivel de bienestar esté por debajo de tal umbral. En cambio, sea cual sea el nivel de bienestar del sujeto estará sufriendo un daño relativo si es verdadero que de no encontrarse en el estado en el que está, se habría encontrado en un mejor. En este caso, sufrir un daño es malo no porque su nivel de bienestar sea menor que el nivel mínimo de bienestar que tiene derecho a tener, sino porque su nivel de bienestar es menor que el nivel de bienestar que habría tenido de otro modo. Esto es así con independencia de que el sujeto afectado se encuentre por arriba o por debajo del umbral de daño absoluto.

\subsection{Comparabilidad de los daños}

Hemos visto que la tesis combinada permite explicar por qué Juan, María y Pedro están sufriendo un daño. En cada uno de los casos, el estado en el que se encuentra cada afectado satisface al menos una condición de la tesis combinada de daño. ¿Significa esto que los daños que ellos están sufriendo son de igual gravedad? O, ¿sufrir un daño por estar en un estado que satisface una de las condiciones es peor que sufrir uno por estar en otro estado que satisface la otra condición? O, si un estado de daño satisface las dos condiciones, ¿significa eso que el daño sufrido es peor que si el estado de daño sólo satisface una condición? Si no respondemos a estas preguntas, aunque podamos considerar que las acciones que causan tales daños son - presumiblemente- incorrectas, todavía no sabremos cuán fuertes son las razones en contra de causar tales daños.

\footnotetext{
${ }^{14}$ Podemos entender a estas como aquellas que se tienen por el sólo hecho de ser humanos, tales como la necesidad de comida, supervivencia, salud, etc. Dado que son básicas, tienen una gran importancia moral. Véase GRIFFIN, James, Well-Being: its Meaning, Measurement and Moral Impact, Oxford: Clarendon Press, 1986, p. 42.
} 
TRUCCONE, Santiago "Un concepto de daño y sus consecuencias para la parte general del derecho penal”.

Las preguntas anteriores asumen que la gravedad de los daños sufridos por los afectados es comparable entre sí. Pero, ¿es esto realmente así? Y si la respuesta es afirmativa, ¿en qué sentido lo son? En algunas situaciones no parece demasiado problemático comparar la gravedad de los daños. Imaginemos que dos hermanos, $\mathrm{X}$ e $\mathrm{Y}$, tienen en sus cuentas bancarias $\$ 10.000 .000$. De repente $\mathrm{X}_{1}$ le sustrae $\$ 100.000$ a $\mathrm{X}$, e $\mathrm{Y}_{1}$ le sustrae $\$ 200.000$ a Y. Así, todo lo demás igual, es posible sostener que el daño que sufre Y es más grave que el que sufre $X$. Para ver por qué esto es así debe notarse que existen dos modos en que los daños pueden diferir entre sí: cuantitativamente o cualitativamente. Dos estados de daño serán cualitativamente diferentes cuando uno satisfaga la condición [a] de la tesis combinada y el otro la condición [b]. En el primer caso, como hemos afirmado, se estará sufriendo un daño absoluto y en el segundo uno relativo. En el caso de los hermanos X e Y no existe diferencia cualitativa entre los daños que ellos están sufriendo. No puede considerarse que tener $\$ 9.900 .000$ y $\$ 9.800 .000$ respectivamente, se encuentra por debajo del umbral de daño. Por tanto, ellos no están sufriendo un daño absoluto. Sin embargo, dado que ambos afectados están en un estado tal que, si dicho estado no hubiese tenido lugar, se habrían encontrado en uno mejor, están sufriendo un daño relativo. No obstante, aunque tanto $\mathrm{X}$ como $\mathrm{Y}$ estén padeciendo un daño de la misma clase, parece que $\mathrm{Y}$ está sufriendo un daño peor dado que la diferencia entre el estado en el que está y aquel en el que habría estado es el doble que la diferencia entre el estado en el que está X y aquel en el que habría estado. En este caso, la diferencia de gravedad entre ambos daños es cuantitativa. Mientras X sufre cierta cantidad de unidades de daño relativo, $\mathrm{Y}$ sufre el doble de unidades del mismo tipo de daño. Como Y sufre más unidades de daño del mismo tipo, el daño que él sufre es peor que el que sufre $X$.

En estos casos, cuando los daños son cualitativamente idénticos, donde un sujeto sufra más de unidades de daño, el daño sufrido será más grave. La noción unidad de daño es aplicable tanto a los daños absolutos como a los relativos. Cada unidad de daño debe ser medida en relación a una línea de base definida. De esta manera tendremos, por un lado, unidades de daño absoluto y, por el otro, unidades de daño relativo. En relación a los daños absolutos, mientras mayor distancia exista entre el estado en el que se encuentra el sujeto y el umbral de daño, mayor será el número de unidades de daño absoluto que esté sufriendo. Del mismo modo, en relación a los daños relativos, mientras mayor sea la distancia que exista entre el estado en que está el sujeto y el estado contrafáctico en el que habría estado si el estado en el que se encuentra no hubiese tenido lugar, mayor cantidad de unidades de daño relativo serán sufridas. Es importante tener presente que nos estamos refiriendo a dos clases de unidades de daño diferentes. Las unidades de daño relativo sirven para medir la gravedad de los daños relativos, en tanto que las unidades de daño absoluto para medir la gravedad de los daños absolutos. Para cada tipo de daño, obviamente, cada unidad de daño tiene el mismo valor. Sin embargo, como analizaremos más adelante, cada unidad de daño absoluto no tiene el mismo valor que cada unidad de daño relativo. Dos personas pueden estar sufriendo un mismo número de unidades de daño, pero si uno de ellos sufre cierto número de unidades de daño absoluto y el otro de daño relativo, el daño que ellos estarán sufriendo puede ser de diferente gravedad.

Con estas consideraciones en mente, ya podemos formular el primer principio sobre la fuerza de las razones en contra de dañar: 
Polít. crim. Vol. 12, № 24 (Diciembre 2017), Art. 14, pp. 1184-1210.

[http://www.politicacriminal.cl/Vol_12/n_24/Vol12N24A14.pdf]

Hemos visto que:

A. X e Y sufren un daño cualitativamente idéntico

B. Y sufre una mayor cantidad de unidades de daño que $X$

C. Y sufre un daño más grave que $X$

Por lo tanto:

D. Si los daños son cualitativamente idénticos, mientras mayor sea la cantidad de unidades de daño sufridas (los daños sean cuantitativamente mayores), los daños sufridos serán más graves.

Hemos afirmado que:

E. A medida que los daños sean más graves las razones en contra de dañar son más fuertes.

Por lo tanto:

Principio I: donde los daños sean cualitativamente idénticos, mientras cuantitativamente más graves sean los daños, más fuertes serán las razones en contra de dañar.

Ahora bien, ¿es posible realizar una comparación similar a la que hemos hecho en relación a $\mathrm{X}$ e $\mathrm{Y}$ cuando nos referimos a los daños que sufren Juan (CASO I), María (CASO II) y Pedro (CASO III). El problema es que -a diferencia de X e Y- Juan, María y Pedro sufren daños cualitativamente diferentes. Juan (CASO I) sufre cierta cantidad de unidades de daño absoluto y cierta cantidad de unidades de daño relativo; María (CASO II) sólo cierta cantidad de unidades de daño absoluto; y Pedro (CASO III) sólo cierta cantidad de unidades relativo. ¿Son comparables estos daños? Un modo de pensar al asunto podría comenzar del siguiente modo: si podemos evitar el daño sufrido por sólo una de un conjunto de personas es razonable pensar que evitaríamos el daño más grave. Imaginemos que podemos o evitar el daño que sufrirá Juan, o el que sufrirá María o el que sufrirá Pedro. ¿Qué daño decidiríamos evitar? Esta pregunta no parece carecer de sentido. Parece que si consideramos cuidadosamente la situación en la que estará cada uno de los afectados es posible determinar cuál es peor. Si esto es así, entonces es plausible pensar que los daños que ellos sufren, aunque sean cualitativamente diferentes, son comparables.

Dejemos, por ahora, fuera del análisis a Juan (CASO I) quien está en un estado que satisface tanto la condición [a] de la tesis combinada de daño - p.ej. sufre un daño absolutocomo la condición [b] - p.ej. sufre un daño relativo. Volvamos, en cambio, a los CASOS II y III, donde cada uno de los afectados está en un estado que sólo satisface una condición de la tesis combinada: María (CASO II) sufre un daño absoluto y Pedro (CASO III) uno relativo. Imaginemos que ya han pasado un par de años desde el nacimiento de María y Pedro. Dado que ya han nacido no hemos podido evitar ningún daño. Lo más que podemos hacer es tomar medidas para mitigar o compensar el daño sufrido. De nuevo, parece que, si 
TRUCCONE, Santiago "Un concepto de daño y sus consecuencias para la parte general del derecho penal”.

sólo podemos tomar medidas en favor de uno, deberíamos hacerlo en favor de la persona que sufre el daño de mayor gravedad. ¿Qué clase de daño es más grave?, esto es, ¿qué clase de daño tiene un efecto peor sobre el bienestar del sujeto afectado?: ¿aquel que afecta el derecho de una persona a tener un nivel mínimo de bienestar, o aquel que hace que su nivel de bienestar sea peor que el que habría tenido de otro modo? Y, por tanto, ¿qué daño deberíamos mitigar o compensar?

Para responder estas preguntas deben añadirse algunos detalles:

Primero, se considera tener una inteligencia normal a la posesión de entre 90 y 109 puntos de cociente intelectual $(\mathrm{CI})^{15}{ }^{16}$. Por lo tanto, es razonable fijar en 90 puntos de CI el umbral de daño referido a las capacidades intelectuales. Así, cualquiera que esté en un estado por debajo de esa marca estará sufriendo un daño absoluto.

Segundo, imaginemos que el médico que trata a la madre de María (CASO II) le informa que, si no espera a que hayan desaparecido los síntomas de Zika antes de concebir, su hijo no podrá tener un CI superior a 50 puntos. Efectivamente, nace María quien tendrá un CI de 50.

Tercero, el médico que trata a la madre de Pedro (CASO III) le informa que Pedro podría tener un CI de 150 puntos, lo que implica tener capacidades intelectuales mayores a las de un "genio". Sin embargo, dado que Petra ha viajado, Pedro tendrá un CI de 110 puntos, capacidad intelectual que se encuentra por arriba de lo normal.

Como estos tres hechos son verdaderos, tanto Pedro como María sufren un daño de 40 unidades. Ambos están a esa distancia de la línea de base en relación a la cual la gravedad del daño debe ser medida ${ }^{17}$. Por lo tanto, los daños sufridos por ambos son cuantitativamente idénticos. Sin embargo, como hemos afirmado, son cualitativamente diferentes: María sufre un daño absoluto por estar debajo del umbral de daño, mientras Pedro sufre un daño relativo por estar en un estado tal que, si el estado en el que se encuentra no hubiese tenido lugar, él estaría en uno mejor. Ahora que conocemos estos hechos es más fácil decidir que daño decidiríamos mitigar o compensar. Imaginemos que la medida para mitigar o compensar los daños consiste en otorgarle ciertos recursos económicos a uno de ellos. Podemos otorgarle los recursos a María, quien está en un estado 40 puntos por debajo umbral de daño; o podemos otorgárselos a Pedro, quien está 40 puntos por debajo del estado en el que habría estado si el estado en el que se encuentra no hubiese tenido lugar. ¿Cómo decidir a quién deben serle otorgados los recursos?

\footnotetext{
${ }^{15}$ WEISS, Lawrence et Al, WISC-IV Advanced Clinical Interpretation, $1^{\mathrm{a}}$ ed., Cambridge: Academic Press, 2006, p. 75.

${ }^{16}$ Por "normal" entenderé aquella capacidad necesaria para afirmar que es posible satisfacer necesidades básicas sin supervisión o asistencia necesaria de otros.

${ }^{17}$ Estoy asumiendo que cada punto de CI es igual a una unidad de daño. Cuando el sujeto habría estado en un mejor estado, cada punto de CI que separa el estado en el que se encuentra el sujeto del estado contrafáctico en el que habría estado, será igual a una unidad de daño relativo. En cambio, cuando un sujeto se encuentre debajo del umbral, cada punto de CI que separa el estado en que está el sujeto del umbral de daño será igual a una unidad de daño absoluto.
} 
Podemos comenzar a responder la pregunta con la siguiente observación. Si un sujeto sufre un daño sólo absoluto y el otro uno sólo relativo, sea cual sea el nivel donde se ha fijado el umbral de daño, el primero tendrá un nivel de bienestar peor que el segundo. Si nos importa que las personas no estén en condiciones o estados malos (badly-off), este hecho apoya la afirmación de que sufrir un daño absoluto es peor que sufrir uno relativo. Para defender tal afirmación podemos apelar a una concepción como la del suficientarismo que afirma que la preocupación por las personas que están debajo del umbral tiene prioridad por sobre la preocupación por cualquier persona que esté por sobre el umbral ${ }^{18}$. Roger Crisp apela a la virtud de la compasión, para explicar tal posición. Su idea es que "El espectador se pone a sí mismo en los zapatos de los afectados y se preocupa más en la medida en que los individuos estén en una peor (mala) condición." Así, la cuestión se convierte en la siguiente: si nos pusiésemos en los zapatos de María y de Pedro, ¿ante quién deberíamos mostrar una preocupación mayor? Creo que no hay problemas en afirmar que ante María en lugar de ante Pedro. Estar en un estado con una vida que no es lo "suficientemente" buena parece ser peor que estar en un estado donde la vida es suficientemente buena pero peor que aquella que, de otro modo, se habría tenido. El hecho de que, a igual cantidad de unidades de daño, estemos dispuestos a compensar daños absolutos antes que daños relativos es indicativo de que los primeros son cualitativamente más graves que los segundos.

Podría objetarse que el suficientarismo no es capaz de apoyar una conclusión como la alcanzada, dado que realiza sus afirmaciones para casos donde lo que está en juego es la distribución de beneficios donde no se está en presencia de acciones incorrectas, y, en el caso bajo análisis, los sujetos a compensar han sido dañados injustamente. Tengo dudas sobre la plausibilidad de esta observación. De hecho, una objeción común a las tesis sobre la distribución de recursos parece asumir que el problema es el inverso. Esto es, aunque pueda ser aceptable que deba mostrarse una preocupación mayor por los sujetos que se encuentran en un peor estado, esto no debería ser así si quien está en ese estado se encuentra allí por sus propias decisiones. ${ }^{20}$ La concepción suficientarista aplicada a los daños sufridos no debe confrontar tal problema. Ninguno de los sujetos se encuentra en un estado de daño debido a su propia decisión. En todos los casos, el sujeto que se encuentra debajo del umbral está sufriendo un daño porque un agente externo causó que esté allí. Por tanto, la objeción falla.

Hemos visto que:

F. María sufre un daño absoluto y Pedro sufre un daño relativo

G. María sufre igual cantidad de unidades de daño que las que sufre Pedro

H. El daño que sufre María es más grave que el que sufre Pedro

\footnotetext{
${ }^{18}$ Esta afirmación es hecha tanto por suficientaristas fuertes como débiles. Ambas posiciones se diferencian en cuán fuerte es la preocupación que se tiene por las personas que están debajo del umbral en relación a aquellas que están sobre el umbral. Mientras los suficientaristas fuertes le otorgan una prioridad léxica a la preocupación por quienes no tienen lo suficiente los suficientaristas débiles sólo afirman que la suficiencia "importa mucho." Véase, FRANKFURT, Harry, "Equality as a Moral Ideal", Ethics 98 (1987), pp. 21-43, p. 21; CASAL, Paula, "Why Sufficiency is Not Enough", Ethics, 117 (2007), pp. 296-326, p. 18

${ }^{19}$ CRISP, Roger "Equality, Priority and Compassion", Ethics 113 (2003), pp. 745-763, p. 757.

${ }^{20}$ ARNESON, Richard, "Luck Egalitarianism and Prioritarianism", Ethics, 110 (2000), pp, 339-49, p. 349.
} 
TRUCCONE, Santiago "Un concepto de daño y sus consecuencias para la parte general del derecho penal”.

Por lo tanto:

I. A igual cantidad de unidades de daño, los daños absolutos son más graves que los daños relativos.

Hemos afirmado que:

E. A medida que los daños sean más graves las razones en contra de dañar son más fuertes.

Por lo tanto:

Principio II: a igual cantidad de unidades de daño, las razones en contra de realizar acciones que causen daños absolutos son más fuertes que las razones en contra de realizar acciones que causen daños relativos.

Hasta aquí, los dos principios formulados pueden resolver situaciones en las que los daños son o cuantitativa o cualitativamente diferentes. Sin embargo, ¿cómo tratar los casos en los que los daños sean tanto cuantitativa como cualitativamente diferentes?, ¿qué sucede cuando, en el mismo caso, se satisfacen las dos condiciones ([a] y [b]) de la tesis combinada daño? El daño, ¿es por este hecho más grave? En el apartado anterior hemos dejado fuera del análisis la situación de Juan (CASO I). Ahora es la oportunidad de analizar si él, quien está en un estado que satisface tanto la condición [a] como la [b] de la tesis combinada de daño, sufre (o no) un daño peor que el que sufre María (CASO II), quién por estar en un estado que sólo satisface la condición [a] sufre un daño más grave que Pedro (CASO III) quien está en un estado que sólo satisface la condición [b] de dicha tesis. Dado que tanto Juan como María tienen un retraso intelectual que los coloca 40 unidades por debajo del umbral de daño, ellos sufren un daño absoluto idéntico. Sin embargo, Juan (pero no María) está en un estado tal que, si dicho estado no hubiese tenido lugar, se habría encontrado en uno mejor. Él (pero no María) habría nacido con capacidades intelectuales que se hubiesen ubicado sobre el umbral de daño. Siendo esto así, ¿quién de los dos está sufriendo un daño que sea peor?

Podría pensarse que, dado que Juan y María están en el mismo estado y tienen un nivel de bienestar equivalente, se encuentran sufriendo un daño de igual gravedad ${ }^{21}$. Sin embargo, creo que es más plausible pensar que si una persona se encuentra en un estado que satisface las dos condiciones ([a] y [b]) de la tesis combinada de daño sufre un daño peor que otra

\footnotetext{
${ }^{21}$ Existen muchas circunstancias de esta clase. Así, por ejemplo, Thomas Pogge explica por qué puede considerarse que el orden global daña a los pobres globales afirmando que el daño que ellos sufren se debe a la injusticia de la situación que padecen. Ante tal circunstancia, sostiene él, nociones de daño como la contrafáctica no deben ser consideradas (POGGE, Thomas, “Assisting' the Global Poor", en: CHATTERJEE, D. (Ed.), The Ethics of Assistance: Morality and Distant Needy, Cambridge: Cambridge University Press, 2004, pp. 260-288, p. 274). Esto implica que, en tal situación, el daño que sufren los pobres globales no sería peor si ellos, además de encontrarse en el estado en el que están, habrían podido estar en uno mejor. Aplicar esta idea a los estados de daño requiere afirmar que, si los daños sufridos pueden explicarse enteramente en términos de daños absolutos, la consideración de dichos daños como -a su vez- relativos no debe ser tenida en cuenta.
} 
Polít. crim. Vol. 12, № 24 (Diciembre 2017), Art. 14, pp. 1184-1210.

[http://www.politicacriminal.cl/Vol_12/n_24/Vol12N24A14.pdf]

que se encuentra en el mismo estado, pero donde sólo se satisface una ${ }^{22}$. Podemos defender esta afirmación mediante la mera aplicación de los dos principios anteriores. Si los daños absolutos son más graves que los relativos y la cantidad de unidades de daño absoluto sufridas por los afectados es idéntica, se sigue que, si uno de ellos sufre además cierta cantidad de unidades de daño relativo, estará sufriendo un daño peor. Por tanto, Juan estaría sufriendo un daño peor que María. Esta conclusión también puede ser defendida de otro modo. Si sufrir un daño absoluto significa que ha sido violado el derecho a tener un nivel mínimo de bienestar, y sufrir un daño relativo significa que el sujeto tiene un nivel de bienestar que es menor que aquel que habría tenido si el estado en que se encuentra no hubiese tenido lugar, entonces cuando uno sufre un daño absoluto y relativo está sufriendo dos males, en tanto que cuando uno sufre un daño absoluto sólo uno. En el caso bajo análisis, mientras tanto Juan como María sufren el mismo daño absoluto dado que ambos se encuentran en el mismo estado debajo del umbral, sólo Juan tiene un nivel de bienestar que es peor que el que habría tenido de otro modo. Es decir, aunque ambos sujetos pueden reclamar que su derecho a tener un nivel mínimo de bienestar ha sido violado, el daño que sufre Juan es peor porque sólo él puede reclamar que, de otro modo, habría tenido un nivel de bienestar mayor al que posee ${ }^{23}$.

Hemos visto que:

J. Juan y María sufren una cantidad X de unidades de daño absoluto

K. Juan sufre una cantidad Y de unidades de daño relativo adicionales

L. El daño que sufre Juan es peor que el que sufre María

Por lo tanto:

M. Sufrir una cantidad X de unidades de daño absoluto y adicionalmente una cantidad Y de unidades de daño relativo es peor que sufrir sólo una cantidad X de unidades de daño absoluto.

Hemos afirmado que:

E. A medida que los daños sean más graves las razones en contra de dañar son más fuertes.

Por lo tanto:

Principio III: las razones en contra de realizar acciones que causen $\mathrm{X}$ unidades de daño absoluto y, adicionalmente, $\mathrm{Y}$ unidades de daño relativo son más

\footnotetext{
${ }^{22}$ Lukas Meyer luego de proponer su concepción disyuntiva sobre las acciones dañosas, parece sostener un punto similar: "Una interpretación plausible de la noción disyuntiva puede ser la siguiente: satisfacer cualquier conjunto de condiciones proporciona una razón para objetar la acción propuesta; si se dan ambos conjuntos de condiciones, la objeción es presumiblemente más fuerte que cuando se da sólo un conjunto de condiciones" (MEYER, "Intergenerational justice" cit. nota, $\mathrm{n}^{\circ}$ 6, p. 34).

${ }^{23}$ Véase HARMAN, Elizabeth, "Harming as Causing Harm", en: ROBERTS, M. \& WASSERMAN D. (Eds.), Harming Future Peoples: Ethics, Genetics and the Non Identity Problem, New York: Springer, 2009, pp. 137-151, p. 146.
} 
TRUCCONE, Santiago "Un concepto de daño y sus consecuencias para la parte general del derecho penal”.

fuertes que las razones en contra de realizar acciones que causen sólo $\mathrm{X}$ unidades de daño absoluto.

\section{Problemas de la parte general del derecho penal}

En esta parte del trabajo me interesa discutir cómo las conclusiones alcanzadas en la primera parte del trabajo pueden ayudar a solucionar algunos problemas del derecho penal. Tal vez pueda parecer extraño que, después de haber buceado en una discusión moral desarrollada principalmente en países de tradición anglosajona, ahora, pretenda llevar algunas conclusiones a sistemas continentales. Sin embargo, es justamente en ese hecho donde reside la riqueza del aporte que se pretende realizar. Los sistemas penales continentales se caracterizan por contar con una construcción conceptual sistemática y robusta para adjudicar responsabilidad penal: la "teoría del delito". De acuerdo a la teoría del delito, para que pueda imponerse justificadamente una pena a una persona es necesario no sólo que haya realizado una acción que cause o pueda causar un daño a alguien (lesión a un bien jurídico, según la terminología continental ${ }^{24}$, sino también que pueda afirmarse que dicha acción es típica, antijurídica y culpable. Los dos primeros elementos conforman lo que se llama injusto penal, en tanto que el último es relevante para conocer la responsabilidad de los agentes. De manera inicial, puede afirmarse que una acción es típica cuando el código penal (o una ley penal) la ha prohibido a través de alguna de sus prescripciones; es antijurídica si no encuentra justificación en el derecho vigente; y es culpable (o responsable) cuando no existen excusas al hecho de haber realizado una acción típica y antijurídica.

Sin embargo, más allá de estas definiciones iniciales de cada estrato analítico, existe un amplio debate sobre cómo precisar sus contornos. El problema es que los teóricos penales continentales clásicos no suelen asignarle mucha importancia a los fundamentos morales, no sólo de cada estrato analítico, sino también de cada teoría utilizada para definir sus contornos. ${ }^{25}$ Esto es problemático desde que, dependiendo de cuál sea la definición que se adopte para cada estrato analítico, las consecuencias normativas serán diferentes. Como las consecuencias son diferentes y, en general, implicarán diferentes grados de afectación coactiva a las personas, es mejor que ellas se encuentren moralmente justificadas.

\footnotetext{
${ }^{24}$ Considero que afirmar que un bien jurídico ha sido lesionado es aproximadamente equivalente a afirmar que alguien está sufriendo un daño. En ambos casos puede afirmarse que el agente que sufre el daño o ha sido lesionado en algún bien jurídico ha visto afectado un interés o un recurso. Para argumentos en favor de esta asunción véase VON HIRSCH, Andrew, "El Concepto de Bien Jurídico y el Principio del Daño" en: HEFENDEHL, Roland (Ed.), La Teoría del Bien Jurídico, Madrid: Marcial Pons, 2007, pp. 37-52. También, véase HASSEMER, Winfried, "The Harm Principle and the Protection of "Legal Goods" (Rechtsgüterschutz): A German Perspective", en: SIMESTER, A., BOIS-PEDAIN, A. \& NEUMANN, U. (Eds.), Liberal Criminal Theory: Essays for Andreas von Hirsch, Oxford: Hart Publishing, 2014, pp. 187-204

${ }^{25}$ Véase NINO, Los Límites a la Responsabilidad Penal, cit. nota ${ }^{\circ}$ 2, pp. 64-100; Véase también NINO, Carlos S., Consideraciones sobre la Dogmática Jurídica: (con referencia particular a la dogmática penal), Universidad Nacional Autónoma de México, 1989, Cap. II.
} 
Polít. crim. Vol. 12, № 24 (Diciembre 2017), Art. 14, pp. 1184-1210.

[http://www.politicacriminal.cl/Vol_12/n_24/Vol12N24A14.pdf]

\subsection{Daños previos y sobredeterminados: el problema de los cursos causales hipotéticos y de causalidad múltiple}

Los daños previos tienen lugar cuando se causa un daño de manera previa a que otro sujeto cause el mismo daño. Los daños sobredeterminados, en cambio, ocurren cuando en un caso tienen lugar dos o más acciones que por sí solas habrían podido causar que alguien sufra un daño. Se ha llamado a la primera situación el problema de los cursos causales hipotéticos y a la segunda el problema de causalidad múltiple, doble causalidad o de los cursos causales alternativos ${ }^{26}{ }_{-2}$. Estos casos han sido especialmente dificultosos para la discusión penal a los fines de calificar como típicas a las acciones que causan daños de ese modo.

En ambos casos, el problema parece estar en el hecho de que para que una condición se considere causa de un resultado, usualmente todo lo que se necesita es que, si dicha condición no hubiese tenido lugar, el resultado no se hubiese producido. Para resolver estas situaciones se han proporcionado una variedad de soluciones relacionadas con el problema causal. Algunos han afirmado que "causa" no es aquella condición necesaria para un resultado sino una que es suficiente, en el sentido de que por sí sola habría hecho que el resultado hubiese tenido lugar, aun si éste se hubiese producido de todos $\operatorname{modos}^{28}$; también se ha hablado de causa como elemento necesario de una mínima condición suficiente ${ }^{29}$; otros han dicho que la causalidad no es el único método para afirmar la existencia de un vínculo entre una acción y un resultado: a la par de ella también existe lo que se denomina nexo de determinación estadístico ${ }^{30}$; finalmente, otros han propuesto adoptar criterios parcialmente normativos para afirmar que una acción es causa de un resultado ${ }^{31}$.

La explicación de por qué, para resolver este problema, se prestó tanta atención a la cuestión de la causalidad puede estar en el hecho de que, para afirmar la tipicidad de una conducta en un delito de resultado se requiere -entre otras cosas- que la acción en cuestión sea causa del resultado lesivo. Sin embargo, aunque la discusión sobre causalidad en estos casos es importante, creo que mucho del desacuerdo e insatisfacción en las soluciones

\footnotetext{
${ }^{26}$ LASCANO, Carlos, "El Tipo Doloso de Comisión”, en: EL MISMO (Ed.), Derecho Penal: Parte General, Córdoba: Editorial Advocatus, 2005, pp.261-292, p. 268.

${ }^{27}$ Un ejemplo del primer problema puede ser el ya trabajado: (El matón y el usurero) "Supóngase que un criminal quiere robar la tienda de joyas de Joaquín. Dado que el robo será más fácil si Joaquín no está en ella, el criminal contrata a un matón para que le quiebre las piernas a Joaquín el día anterior al robo. Cuando el matón llega a la casa de Joaquín, sin embargo, encuentra que el usurero local ya ha roto sus piernas". Un ejemplo clásico del segundo tipo de situaciones, traído por Roxín es aquel donde “A y B, actuando independientemente uno del otro, ponen veneno en el café de $\mathrm{C}$; $\mathrm{C}$ muere por ello, pero la dosis colocada por A y por B hubiera provocado por sí sola la muerte exactamente del mismo modo al mismo momento." (ROXIN, Claus, Derecho Penal, Parte General, Tomo I: fundamentos de la estructura de la teoría del delito, Madrid: Civitas [Trad. D. Luzón Peña, M. Díaz y García Conlledo, J. de Vicente Remesal], 1997[1994], p. $350)$.

${ }^{28}$ ROXIN, Derecho Penal, cit. nota ${ }^{\circ} 27$, p. 354

${ }^{29}$ PUPPE, Ingeborg, "The Concept of Causation in the Law", en: KAHMEN, B. \& STEPANIANS, M (Eds.), Critical Essays on "Causation and Responsibility", Berlin: De Gruyter, 2013, pp. 67-109, p. 101

${ }^{30}$ PÉREZ BARBERÁ, Gabriel, "Causalidad y Determinabilidad”, en: AA.VV., Nuevas Formulaciones de las Ciencias Penales. Libro homenaje a Claus Roxín, Córdoba: Lerner, 2001, pp. 87-137; PÉREZ BARBERÁ, Gabriel, "Infracción Punible de Deberes de Tolerancia: El problema de la Causalidad", Revista Discusiones, No 7 (2007), pp. 79-111, p. 98 y 108.

${ }^{31}$ BACIGALUPO, Enrique, Principios de Derecho Penal: Parte General, Madrid: Akal/Iure, 1997, p. 188.
} 
TRUCCONE, Santiago "Un concepto de daño y sus consecuencias para la parte general del derecho penal".

propuestas se debe a que no se ha atendido debidamente a qué significa que alguien está sufriendo un daño o qué significa que un bien jurídico haya sido lesionado: ¿cómo es posible saber si determinada acción causó (o determinó) un daño o una lesión a un bien jurídico si no se sabe exactamente qué significa que alguien esté sufriendo un daño o que un bien ha sido lesionado? La tesis combinada de dañar puede aportar claridad aquí.

Si se acepta esta tesis, el problema de los cursos causales hipotéticos (daños previos) ya no parece presentar un inconveniente de difícil solución. De acuerdo a la tesis combinada alguien está sufriendo un daño cuando se encuentra en un estado que satisface o la condición [a] o [b]; quien haya ocasionado que alguien esté en tal estado habrá causado tal daño. El hecho de que, en ausencia de la acción dañosa otra persona habría ocasionado el mismo daño con posterioridad no plantea ningún problema especial. Esto es, tal hecho no socava la afirmación de que el sujeto que obró en primer lugar ha dañado (lesionado algún bien jurídico) al sujeto pasivo. Un razonamiento similar puede aplicarse para resolver los casos de causalidad múltiple (daños sobredeterminados). Sin embargo, a diferencia del caso anterior, la tesis combinada de dañar requerirá el apoyo de alguna teoría de la causalidad que, en lugar de considerar causa a aquella condición necesaria para ocasionar un resultado, o bien se considere causa a aquella que es suficiente para hacerlo; o bien se descanse en la noción de elemento necesario de una mínima condición suficiente; o bien una que se apele a algún criterio estadístico que permita determinar el nexo entre tal resultado y el hecho que lo ocasionó; o bien se añada algún componente normativo al concepto de causalidad.

\subsection{Estado de necesidad: sobre la distinción entre justificación y excusa}

El estado de necesidad justificante tiene lugar cuando el mal evitado es mayor al producido, en tanto que el estado de necesidad exculpante cuando esto no ocurre ${ }^{32}$. Cuando el estado de necesidad justificante tiene lugar, la acción en cuestión no será antijurídica y, por tanto, estará justificada. En cambio, cuando el estado de necesidad es exculpante, la acción en cuestión será típica y antijurídica, pero quien la realice no será responsable por ella. Para distinguir cuándo se esté en presencia de uno u otro supuesto se apela a la gravedad de los males en juego ${ }^{33}$. Para graduar la gravedad de los males generalmente se recurre a dos criterios: en primer lugar, a la jerarquía de los bienes jurídicos en juego; y, en segundo lugar, al grado de lesión ${ }^{34}$. Así, es ampliamente sostenido que, como regla general, si el bien jurídico lesionado es de menor jerarquía que el defendido se estará en presencia de un estado de necesidad justificante, mientras que, si son de igual jerarquía, el estado de

\footnotetext{
${ }^{32}$ La regulación legal argentina es la siguiente: en relación al estado de necesidad justificante prescribe art. 34 inc. 3 del Código Penal (C.P): "No son punibles: el que causare un mal por evitar otro mayor inminente del que ha sido extraño". En tanto que el inc. 2. del Art. 34 se refiere al exculpante: "No son punibles: el que obrare violentado por (...) amenazas de sufrir un mal grave e inminente."

${ }^{33}$ Por supuesto, además de la diferencia de gravedad de los males en juego tienen que darse otros requisitos tales como la inminencia, ajenidad e inevitabilidad del mal por un medio menos lesivo (véase ZAFFARONI, E. R, ALAGIA A. y SLOKAR, A, Derecho Penal: Parte General, Buenos Aires: Ediar, 2002, pp. 631-636). Sin embargo, aquí nos focalizaremos sólo sobre la diferencia entre gravedad de males en juego.

${ }^{34}$ Esta apreciación es compartida en varios sistemas de tradición continental. Véase ROXIN, Derecho Penal, cit. nota ${ }^{\circ}$ 27, pp. 684-685. NUÑEZ, Ricardo, Manual de Derecho Penal: Parte General, Córdoba: Lerner, 1999, p. 161; ZAFFARONI, Eugenio R., Estructura Básica del Derecho Penal, Buenos Aires: Ediar, 2009, p. 201.
} 
necesidad será exculpante. Esto tiene sentido desde que parece que, al menos en algunos casos, no hay nada de incorrecto en causar cierto daño para evitar uno mayor. Obviamente, no siempre que el bien salvado sea de mayor jerarquía que el lesionado, la acción estará justificada. Para la distinción entre estado de necesidad justificante y exculpante, entra en juego también el grado de lesión al bien jurídico. Así, si el grado de lesión provocado es menor al grado de lesión evitado, si es de aplicación el estado de necesidad debe serlo a título de justificación. De acuerdo a estos criterios, pareciera que, si el bien ofendido es de la misma jerarquía que el defendido, y la cantidad de unidades de daño producidas y evitadas (grado de lesión al bien jurídico) son equivalentes, entonces se sigue que si algún estado de necesidad es aplicable será el exculpante y no el justificante.

Sin embargo, de acuerdo a las consideraciones referidas a la gravedad de los daños defendidas arriba esto no es así. Puede ser que los bienes lesionados sean de igual jerarquía y el grado de lesión producido sea equivalente y no deba aplicarse el estado de necesidad exculpante sino el justificante. Tan pronto como los daños sobre un mismo bien pueden diferir cualitativamente, esto es, entre absolutos y relativos, debe decirse algo más en relación a los criterios de distinción entre un estado de necesidad y el otro. La propuesta es la siguiente. Aceptamos, como parece plausible, que el estado de necesidad justificante tiene lugar cuando el mal evitado es mayor al producido, en tanto que el estado de necesidad exculpante cuando esto no ocurre. Sin embargo, para distinguir la gravedad de los males en juego, en lugar de apelar a la jerarquía de bienes y grado de lesión, debemos apelar a las conclusiones que hemos alcanzado sobre cuándo un daño sufrido es de mayor gravedad que otro. La idea es que la apelación a la gravedad del daño causado -tal y como ha sido defendido en el punto 1 de este trabajo- es el criterio que debemos utilizar para saber, si es de aplicación el estado de necesidad, lo es a modo de justificación o excusa. Seguir esta propuesta permitirá que la aplicación del estado de necesidad esté no sólo moralmente justificada sino también solucionar -como se verá- ciertos problemas que se han mostrado especialmente espinosos apelando meramente a la distinta jerarquía de bienes jurídicos y grado de lesión producido.

Analizaremos la aplicación de la propuesta a través de un caso hipotético similar a los que hemos trabajado en los capítulos previos para, luego, virar la discusión a algunos casos reales.

\subsubsection{CASO IV - (Matías):}

Matilda está embarazada. El médico le ha informado que, si el embarazo continúa en sus carriles normales, su hijo -Matías- tendrá no sólo casi ningún riesgo de padecer cáncer, problemas cardíacos, o alzhéimer, sino también una inteligencia superior de 170 puntos de CI. Matilda ha contraído una rara enfermedad que le afectará sus capacidades intelectuales. Las capacidades intelectuales actuales de Matilda son normales: 90 puntos de CI. Pero si no hace nada en contra de la enfermedad de manera urgente, ella pasará a tener cierto retraso intelectual: 65 puntos de CI. Afortunadamente, existe un tratamiento que puede seguir para no caer por debajo del umbral de normalidad. Sin embargo, ella sabe que este tratamiento hará que el hijo que porta en su seno, en lugar de nacer con 170 puntos de CI., lo haga con 
TRUCCONE, Santiago "Un concepto de daño y sus consecuencias para la parte general del derecho penal”.

uno de 120. Matilda se somete al tratamiento, evita caer por debajo del umbral y causa que su hijo tenga un C.I. 50 puntos menor a aquel que habría tenido de otro modo ${ }^{35}$.

Veamos el caso en detalle:

\begin{tabular}{|l|l|l|l|}
\hline & Estado Real & Estado Posible & Unidades de Daño \\
\hline Matilda & 90 & 65 & $(25$ absoluto +25 relativo $)$ \\
\hline Matías & 120 & 170 & $(50$ relativo $)$ \\
\hline Umbral de Daño: 90 & \multicolumn{2}{|l}{} \\
\hline
\end{tabular}

Matilda se encuentra amenazada por un mal grave e inminente. Si ella no obra de manera urgente, dado que tendrá 65 puntos de CI cuando el umbral de daño ha sido fijado en 90 , padecerá 25 unidades de daño absoluto en su integridad intelectual. Asimismo, dado que tendrá un CI 25 unidades peor que aquel que habría tenido si el estado en el que se encontrara no hubiese tenido lugar, ella estará sufriendo 25 unidades de daño relativo. En total, por tanto, ella está amenazada con sufrir un daño de 50 unidades: 25 absoluto y 25 relativo. Sin embargo, ella puede evitar este mal mediante la realización de un tratamiento. En este caso, dado que no habrá sufrido las 50 unidades de daño, habrá evitado el mal que la amenaza. No obstante, su acción provocará un mal en su hijo: dado que Matías pasará de tener 170 puntos de CI a 120, también sufrirá un daño en la integridad intelectual de 50 unidades. Si aplicáramos los dos criterios usuales, es decir jerarquía de bienes y grado de lesión, tendríamos que afirmar que la acción de Matilda sólo puede estar exculpada (y no justificada). Esto porque las dos posibles lesiones, la evitada y la provocada, versan sobre el mismo bien jurídico: integridad intelectual; además, dado que las unidades de daño producidas y evitadas son cuantitativamente idénticas, parece que el grado de lesión al bien jurídico es equivalente.

Sin embargo, si graduamos la gravedad de los males teniendo en cuenta la diferente gravedad de los daños en juego, la respuesta sería diferente. Hemos afirmado que los daños pueden diferir tanto cuantitativa como cualitativamente. Asimismo, que cuando los daños son cuantitativamente idénticos sufrir un daño absoluto es peor que sufrir uno relativo. En el caso bajo análisis, Matilda se encuentra amenazada por el mal de sufrir 50 unidades de daño, 25 de las cuales serán de daño absoluto. En cambio, el daño que ella le causará a Matías, si bien también será de 50 unidades, todas ellas serán de daño relativo. Como hemos afirmado que, a igual cantidad de unidades de daño, sufrir un daño absoluto representa un daño peor que sufrir un daño relativo, podemos sostener -de manera justificada- que el mal que ha evitado Matilda con su accionar es mayor al que ha causado. Por tanto, si en este caso es de aplicación el estado de necesidad, debe serlo a modo de justificación y no de excusa.

Aunque el ejemplo previo pueda parecer irreal, y sospechosamente preciso, es útil para observar cómo opera la tesis propuesta. La distinción entre daños absolutos y relativos ayuda a explicar de mejor modo y de manera más simple casos problemáticos que han

\footnotetext{
35 Este caso tampoco se encuentra muy lejano al mundo real. Podría pensarse que la madre contrajo un absceso cerebral. Asimismo, que el tratamiento seguido consiste en tomar un antibiótico como el cloranfenicol, el que, aunque cura a la madre puede producir graves consecuencias para el desarrollo del feto.
} 
Polít. crim. Vol. 12, № 24 (Diciembre 2017), Art. 14, pp. 1184-1210.

[http://www.politicacriminal.cl/Vol_12/n_24/Vol12N24A14.pdf]

requerido criterios adicionales, a los de jerarquía de bienes y grado de lesión al bien jurídico, para obtener una resolución justa. Se ha hablado de ponderación de intereses en lugar de jerarquía de bienes, para mostrar que, por ejemplo, el interés en los asuntos comerciales de un implicado en un accidente automotor no es suficiente para justificar que se marche del lugar en comparación con los intereses del otro sujeto implicado en que se comprueben los datos para obtener una indemnización por daños y perjuicios ${ }^{36}$. Si se aplicara la tesis aquí propuesta, todo lo que sería necesario para llegar a la misma solución sería comprobar que el daño sufrido por una de las partes, aunque en el mismo bien jurídico y en el mismo grado de lesión, es absoluto, en tanto que el sufrido por el otro, relativo.

También se ha hablado de importancia esencial de los intereses protegidos para sostener, por ejemplo, que está justificado poner en libertad a algún condenado por terrorismo para rescatar a algún rehén ${ }^{37}$. Si se aplicara la tesis aquí propuesta no sería necesario apelar a tal criterio. Parece obvio que, aunque los dos sujetos estén privados de la libertad, la injusticia de la situación hace que el daño que sufre el rehén pueda caracterizarse como absoluto, mientras que no es obvio que el condenado a prisión esté sufriendo un daño absoluto. También se ha propuesto considerar las circunstancias personales de los respectivos titulares. A través de este criterio se pretende defender que en algunos casos en los que, en relación al mismo bien jurídico, el mal evitado parece ser mayor al causado, debe aplicarse estado de necesidad exculpante y no justificante. Un caso de este tipo sería aquel donde un ganadero, para salvar a 10 de sus animales, mata a la única vaca de su vecino ${ }^{38}$. Si se aplicara la tesis aquí propuesta podría llegarse a la misma conclusión sin necesidad de apelar a ningún criterio adicional. El granjero ha ocasionado un daño absoluto a su vecino debido a que lo ha dejado sin lo suficiente. Incluso más, no tener ninguna vaca tiene que significar que el sujeto afectado se encuentra muy lejos del umbral de daño. Sin embargo, el daño que ha evitado el ganadero es meramente relativo. Así, dado que los daños absolutos son más graves que los relativos, no es posible afirmar que la acción del ganadero ha estado justificada.

\subsection{Culpabilidad e individualización de la pena}

El análisis sobre la culpabilidad (responsabilidad), como estrato analítico dentro de la teoría del delito, parte de la idea de responsabilidad individual y pretende determinar si determinado injusto puede ser reprochado. En sí, involucra una serie de discusiones heterogéneas que van desde (a) la posibilidad de que el agente haya conocido la regla penal prohibitiva; (b) su capacidad de imputabilidad; hasta (c) la exigibilidad de una conducta conforme a derecho ${ }^{39}$. En relación a estos temas, la mayor parte de la discusión ha girado en torno a si una acción que es típica y antijurídica también debe (o no) considerarse como culpable, de manera tal que la imposición de una pena se encuentre justificada. Sin embargo, mucho menos se ha discutido sobre cuánta pena corresponde cuando se da por probado que tienen lugar los elementos que involucra la culpabilidad.

\footnotetext{
${ }^{36}$ ROXIN, Claus, Derecho Penal, cit. nota ${ }^{\circ} 27$, p. 686

${ }^{37}$ JESCHECK, Hans, Tratado de Derecho Penal: Parte General, Granada: Comares, 2002, p. 389.

${ }^{38}$ ZAFFARONI/ALAGIA/SLOKAR, Derecho Penal, cit. nota n ${ }^{\circ} 33$, p. 639.

${ }^{39}$ BALCARCE, Fabián, "Introducción al Estudio de la Parte Especial del Derecho Penal", en: EL MISMO (Ed.), Lecciones de Derecho Penal: Parte Especial, T. I, Córdoba: IPSO, 2016, pp. 11-113, p. 95.
} 
TRUCCONE, Santiago "Un concepto de daño y sus consecuencias para la parte general del derecho penal”.

Una vez que los extremos anteriores han sido satisfechos, el modo más extendido de individualización de la pena a imponer en el caso concreto es atarla a una teoría de la pena concreta. Por ejemplo, se apela a lo que se conoce como la teoría del espacio de juego (Spielraum) de acuerdo a la cual una pena adecuada a la culpabilidad comprende un marco determinado entre un máximo y un mínimo ${ }^{40}$. Dicho marco sería el "espacio de juego" dentro del cual el Juez gradúa la pena correspondiente a una culpabilidad específica en el caso concreto atendiendo a, por ejemplo, las necesidades preventivas que pueda haber ${ }^{41}$. Se suele afirmar que la medida de la pena a imponer está dada por su utilidad social, claro que, sin traspasar el límite de la culpabilidad ${ }^{42}$. Sin embargo, este modo de entender el asunto presenta un problema. Considerar a la culpabilidad como único límite a la utilidad, si bien garantiza que las penas no superen lo merecido, no asegura una distribución equitativa del castigo entre los ciudadanos que cometen delitos. Para esto, es necesario un criterio que permita castigos de diferente intensidad en función de distintos grados de culpabilidad por el hecho cometido ${ }^{43}$.

Conforme a un criterio de culpabilidad bastante razonable, lo que se le reprocha al autor es haber realizado una acción típica y antijurídica cuando pudo haber obrado de otro modo. Además, si -como parece plausible- la culpabilidad es una cuestión de grados, tendríamos que preguntar "cuánto" el sujeto pudo actuar de otro modo. Esta pregunta aparenta ser absurda en el sentido de que no parece que poder o no actuar de uno u otro modo sea una cuestión de grados. Parece que, o bien es posible haber actuado de otro modo o, por el contrario, no lo es ${ }^{44}$. Sin embargo, existe otra pregunta que puede ser relevante a estos fines que no parecer ser para nada absurda. Si se sostiene que lo que se le reprocha al autor es haber realizado una acción cuando pudo haber obrado de otro modo, el reproche puede ser graduado no en función de "cuánto" haya podido obrar de otro modo, sino en función de cuán fuertes eran las razones en contra o a favor de tomar tal o cual curso de acción ${ }^{45}$. Los principios (I, II, III) pueden ayudar aquí.

La propuesta es la siguiente: mientras más fuertes son las razones en contra de adoptar un curso de acción que, de acuerdo a derecho es típico y antijurídico, mayor será el reproche de culpabilidad. $\mathrm{Si}$, como hemos afirmado, mientras peor es el daño causado, más fuertes

\footnotetext{
${ }^{40}$ PESCE LAVAGGI, Eduardo, La Individualización de la Pena en Nuestro Ordenamiento Jurídico Penal, Montevideo: Carlos Álvarez, 2003, p. 16.

41 DRUBBER, Marcus y HÖRNLE, Tatjana, Criminal Law: A comparative Approach, Oxford: Oxford University Press, 2014, p. 15.

${ }^{42}$ ROXIN, Derecho Penal, cit. nota ${ }^{\circ} 27$, p. 792.

43 PERALTA, José, "Dogmática del Hecho Punible, Principio de Igualdad y Justificación de Segmentos de Pena", Doxa: Cuadernos de Filosofía del Derecho, N³1(2008), pp. 599-624, pp. 612-613.

44 HÖRNLE, Tatjana, "La Concepción Anticuada de la Culpabilidad en la Jurisprudencia y Doctrina Tradicionales de la Medición de la Pena", ADPCP, Vol. LIV (2001), pp. 401-429, p. 413.

${ }^{45}$ Esta propuesta se basa en el hecho de que [a] como seres racionales tenemos la capacidad de entender y responder a razones; [b] las razones son proporcionadas por hechos; [c] diferentes hechos proporcionan razones de diferente fuerza; [d] respondemos a esas razones cuando conocemos los hechos que nos llevan a hacer o tratar de hacer lo que tenemos razones para hacer. La conjunción de estos elementos ([a], [b], [c], [d]) nos permite afirmar que si conocemos todos los hechos relevantes, como seres racionales seremos pasibles de una mayor culpabilidad en la medida en que nuestra respuesta a las razones sea contraria a lo que ellas indican. En este esquema sigo a PARFIT, Derek, On What Matters, Vol. I, Oxford: Oxford University Press, 2011, Cap. I, II y VI.
} 
son las razones en contra de dañar y, si mientras más fuerte son las razones en contra de dañar, mayor es la culpabilidad, entonces, mientras peor sea el daño causado, mayor será la culpabilidad. También hemos afirmado que, a mayor culpabilidad, mayor pena. Por lo tanto, mientras peores sean los daños causados, mayor será la pena que tendremos que imponer. Hasta aquí, la propuesta es compatible con afirmar que la pena debe ser graduada meramente de acuerdo a la gravedad del daño causado.

Sin embargo, los principios sobre la fuerza de las razones en contra de dañar proporcionan un servicio adicional. Nos permiten graduar la culpabilidad de los agentes teniendo en cuenta hechos diferentes al daño causado. Cada uno de los principios fue diseñado para resolver situaciones de conflicto donde en cursos de acción alternativos se producirían daños de diferente gravedad. La graduación de la fuerza de las razones en contra de producir determinados daños, no sólo tiene que ver con el posible daño causado sino también con los daños que no han sido causados al momento de tomar tal o cual curso de acción. Un ejemplo puede aclarar el asunto: la fuerza de las razones en contra de ocasionar que alguien sufra un daño en algún bien determinado de, por ejemplo, 50 unidades no es siempre idéntica. Dependerá no sólo de qué tipo de daño (absoluto o relativo) sea el causado, sino también de cuales sean los posibles daños causados por las acciones alternativas disponibles. Si la alternativa era causar 60 unidades de daño absoluto, entonces la fuerza de las razones en contra de causar 50 unidades de -por ejemplo- daño absoluto, es más débil que lo que hubiesen sido si en el curso de acción alternativo se hubiesen causado o bien 50 unidades de daño relativo o ninguna unidad de daño. Esto sería así, aunque en cada una de estas situaciones, el sujeto en cuestión haya realizado la misma acción típica y antijurídica. En estos casos, como la fuerza de las razones en contra de haber realizado tal acción sería diferente, la culpabilidad también lo será y, por tanto, la pena que debe ser impuesta.

En síntesis, ante la realización de un hecho X, mientras más fuertes sean las razones en contra de realizarlo, más culpables seremos y, por tanto, mayor pena debe sernos impuesta. Si estas consideraciones son correctas, entonces, la utilización de los principios sobre la fuerza de las razones en contra de dañar, nos permite graduar diferentes montos de pena en función de la diferente culpabilidad de los agentes. Por lo tanto, haciendo - de ese modoque la distribución del castigo entre los ciudadanos que cometen delitos sea más equitativa. Si mi propuesta es correcta, es también falso que el juicio de culpabilidad no puede incrementar el merecimiento de pena ya alcanzado con la realización del hecho, sino sólo excluirlo o disminuirlo $^{46}$. Luego de analizar cuánta pena debe imponerse en función del injusto cometido, ésta todavía puede variar en función de cuán culpable sea el acto realizado. Culpabilidad que puede ser graduada en función de cuán fuertes hayan sido las razones en contra de actuar del modo en que se lo hizo 47 .

\footnotetext{
${ }^{46}$ SILVA SÁNCHEZ, Jesús, "La Teoría de la Determinación de la Pena como Sistema (dogmático): un primer esbozo, InDret 2/2007, pp.1-9, p. 9.

${ }^{47}$ Una aclaración adicional para evitar malos entendidos: la propuesta no implica que se deba imponer una mayor pena cuando los motivos (actitud interna) del agente que lo llevó a delinquir sean más reprochables. Como hemos afirmado, la fuerza de las razones en contra de dañar ( $\mathrm{y}$ en contra o a favor de realizar cualquier curso de acción) no derivan de una actitud interna del agente, sino que son proporcionadas por los daños, tanto el causado como los que hubiesen tenido lugar si se hubiese realizado algún curso de acción alternativo.
} 
TRUCCONE, Santiago "Un concepto de daño y sus consecuencias para la parte general del derecho penal”.

\section{Conclusiones}

En este trabajo comenzamos proporcionando argumentos en favor de una noción combinada de daño. De acuerdo a esta noción, una persona sufre un daño solo si [a] está en un estado por debajo del umbral, o [b] está en un estado $\mathrm{E}$ tal que, si $\mathrm{E}$ no hubiese tenido lugar, esa persona se habría encontrado en un estado mejor. Hemos afirmado que la gravedad entre diferentes daños puede variar no sólo en términos cuantitativos sino también cualitativos. Asimismo, como hemos afirmado que mientras peor sean los daños sufridos más fuertes serán las razones en contra de dañar, hemos formulado tres principios sobre la fuerza de las razones en contra de dañar.

Estas conclusiones son importantes porque ayudan a resolver algunos problemas propios de la parte general del derecho penal. Hemos argumentado, primero, que la tesis combinada de dañar puede ayudar a resolver casos de causalidad alternativa y múltiple. Segundo, sostuvimos que la diferencia en cuanto a la gravedad de los daños causados ayuda a distinguir situaciones de estado de necesidad justificante y exculpante. Finalmente, defendimos que los principios sobre la fuerza de las razones en contra de dañar sirven de guía para individualizar la pena a imponer de acuerdo a la culpabilidad del agente en cuestión. Hemos afirmado que ella puede ser graduada en función de no sólo las razones derivadas del daño causado sino también de aquel daño que no se ha causado al elegir actuar cómo se hizo. 
Polít. crim. Vol. 12, No 24 (Diciembre 2017), Art. 14, pp. 1184-1210.

[http://www.politicacriminal.cl/Vol_12/n_24/Vol12N24A14.pdf]

\section{BIBLIOGRAFÍA}

ARNESON, Richard, "Luck Egalitarianism and Prioritarianism", Ethics, 110 (2000), pp, 339-49.

BACIGALUPO, Enrique, Principios de Derecho Penal: Parte General, Madrid: Akal/Iure, 1997.

BALCARCE, Fabián, "Introducción al Estudio de la Parte Especial del Derecho Penal", en: EL MISMO, (Ed.), Lecciones de Derecho Penal: Parte Especial, T. I, Córdoba: IPSO, 2016, pp.11-113.

CASAL, Paula, "Why Sufficiency is Not Enough", Ethics 117 (2007), pp. 296-326.

CRISP, Roger, "Equality, Priority and Compassion", Ethics 113 (2003), pp. 745-763.

DEVLIN, Patrick, "Morals and the Criminal Law", en: WASSERSTROM, R. (Ed.), Morality and the Law, Belmont: Wadsworth Publishing Company, 1971[1965], pp. 24-48.

DILLARD, Carter, "Procreation, Harm and the Constitution", Northwestern University Law Review, Vol. 105 (2010), pp. 5-17.

DRUBBER, Marcus y HÖRNLE, Tatjana, Criminal Law: A comparative Approach, Oxford: Oxford University Press, 2014.

DUFF, R. A., Answering for Crime: Responsibility and Liability in the Criminal Law. Oxford: Hart Publishing, 2007.

FEINBERG, Joel Harm to Others: The Moral Limits of Criminal Law, Vol I. Oxford University Press, 1984

FRANKFURT, Harry, "Equality as a Moral Ideal”, Ethics 98 (1987), pp. 21-43.

GARDNER S. y SHUTE S., "The Wrongness of Rape" en: HORDER, Jeremy (Ed.), Oxford Essays in Jurisprudence: Fourth Series, Oxford: Oxford University Press, 200, pp. 199-217.

GARDNER, Molly, "On the Strength of the Reason Against Harming", Journal of Moral Philosophy, Leiden: Brill, 2015, pp. 1-15.

, "The Problem of Justified Harm", Ethical Theory and Moral Practice (inédito), 2017, pp. 1-19.

GRIFFIN, James, Well-Being: its Meaning, Measurement and Moral Impact, Oxford: Clarendon Press, 1986.

HANSER, Matthew, "The Metaphysics of Harm", Philosophy and Phenomenological Research, Vol. LXXXVII, N 2 (2008), pp. 421-450.

HARMAN, Elizabeth, "Harming as Causing Harm", en: ROBERTS, M., \& WASSERMAN, D. (Eds.), Harming Future Peoples: Ethics, Genetics and the Non Identity Problem, New York: Springer, 2009, pp. 137-151.

HART, H.L.A., Law, Liberty and Morality, Oxford: Oxford University Press, 1962.

HASSEMER, Winfried, "The Harm Principle and the Protection of "Legal Goods" (Rechtsgüterschutz): A German Perspective", en: SIMESTER, A., BOIS-PEDAIN, A. \& NEUMANN, U. (Eds.), Liberal Criminal Theory: Essays for Andreas von Hirsch, Oxford: Hart Publishing, 2014, pp. 187-204.

HÖRNLE, Tatjana, "La Concepción Anticuada de la Culpabilidad en la Jurisprudencia y Doctrina Tradicionales de la Medición de la Pena" ADPCP, Vol. LIV (2001), pp. 401-429.

JESCHECK, Hans, Tratado de Derecho Penal: Parte General, Granada: Comares, 2002. 
TRUCCONE, Santiago "Un concepto de daño y sus consecuencias para la parte general del derecho penal".

LASCANO, Carlos, “El Tipo Doloso de Comisión” en: EL MISMO, (Ed.), Derecho Penal: Parte General, Córdoba: Advocatus, 2005, pp.261-292.

MEYER, Lukas, "Past and Future: The Case for a Threshold Notion of Harm", en: MEYER, L., PAULSON, S. y POGGE, T. (Eds.), Rights, Culture, and the Law: Themes from the Legal and Political Philosophy of Joseph Raz, Oxford: Oxford University Press, 2003, pp. 143-159.

"Intergenerational Justice", en: ZALTA, Edward N. (Ed.), The Stanford Encyclopaedia of Philosophy, Stanford: Stanford University Metaphysics Research Lab, 2015, pp. 1-101, disponible en: http://plato.stanford.edu/archives/win2015/entries/justice-intergenerational/

MEYER Lukas y ROSER, Dominic, "Enough for the Future", en: GOSSERIES, A. y MEYER, L. (Eds.), Intergenerational Justice, Oxford: Oxford University Press, 2009, pp. 219-248.

MILL, John Stuart, On Liberty, [D. Bromwich and G. Kateb (eds.)], New Haven: Yale University Press, 2008 [1859].

NINO, Carlos S., Los Límites a la Responsabilidad Penal: una Teoría Liberal del Delito, Buenos Aires: Astrea, 1980.

, Consideraciones sobre la Dogmática Jurídica: (con referencia particular a la dogmática penal), Universidad Nacional Autónoma de México, 1989.

NUÑEZ, Ricardo, Manual de Derecho Penal: Parte General, Córdoba: Lerner, 1999.

PARFIT, Derek, Reasons and Persons, Oxford: Clarendon Press, 1987.

, On What Matters, Vol. I, Oxford: Oxford University Press, 2011.

PERALTA, José, "Dogmática del Hecho Punible, Principio de Igualdad y Justificación de Segmentos de Pena" Doxa: Cuadernos de Filosofía del Derecho, 31 (2008), pp. 599624.

PÉREZ BARBERÁ, Gabriel, "Causalidad y Determinabilidad" en: AA.VV., Nuevas Formulaciones de las Ciencias Penales. Libro homenaje a Claus Roxín, Córdoba: Lerner, 2001, pp. 87-137.

, "Infracción Punible de Deberes de Tolerancia: El problema de la Causalidad" Revista Discusiones, $\mathrm{N}^{\circ} 7$ (2007), pp. 79-111.

PESCE LAVAGGI, Eduardo, La Individualización de la Pena en Nuestro Ordenamiento Jurídico Penal, Carlos Álvarez, Montevideo, 2003

POGGE, Thomas, "'Assisting' the Global Poor", en: CHATTERJEE, D. (Ed.), The Ethics of Assistance: Morality and Distant Needy, Cambridge: Cambridge University Press, 2004, pp. 260-288.

PUPPE, Ingeborg, "The Concept of Causation in the Law", en: KAHMEN, B. \& STEPANIANS, M. (Eds.), Critical Essays on "Causation and Responsibility", Berlin: De Gruyter, 2013, pp. 67-109.

ROXÍN, Claus, Derecho Penal, Parte General, Tomo I: fundamentos de la estructura de la teoría del delito, Madrid: Civitas [Trad. D. Luzón Peña, M. Díaz y García Conlledo, J. de Vicente Remesal], 1997[1994].

SILVA SÁNCHEZ, Jesús, "La Teoría de la Determinación de la Pena como Sistema (dogmático): un primer esbozo", InDret 2/2007, pp.1-9.

VON HIRSCH, Andrew, "El Concepto de Bien Jurídico y el Principio del Daño", en: HEFENDEHL, Roland (Ed.), La Teoría del Bien Jurídico, Madrid: Marcial Pons, 2007, pp. 37-52. 
Polít. crim. Vol. 12, № 24 (Diciembre 2017), Art. 14, pp. 1184-1210.

[http://www.politicacriminal.cl/Vol_12/n_24/Vol12N24A14.pdf]

WEISS, Lawrence, at Al, WISC-IV Advanced Clinical Interpretation, $1^{\mathrm{a}}$ ed., Cambridge: Academic Press, 2006.

ZAFFARONI, Eugenio R., Estructura Básica del Derecho Penal, Buenos Aires: Ediar, 2009.

ZAFFARONI, E. R, ALAGIA A. y SLOKAR, A, Derecho Penal: Parte General, Buenos Aires: Ediar, 2002. 